\title{
Çok boyutlu yazıcılardan baskısı farklı parametrelerle alınan numunelerin malzeme seçiminin deneysel analizi
}

\author{
Experimental analysis of material selection of samples printed with different parameters \\ from multidimensional printers
}

\author{
Kadir BEKAR ${ }^{1, a}$, Ufuk ÇIFCI*2,b, Arif ÖZKAN ${ }^{3, c}$ \\ ${ }^{1}$ Düzce Üniversitesi, Fen Bilimleri Enstitüsü, Kompozit Malzeme Teknolojileri Bölümü, 81620, Düzce \\ ${ }^{2}$ Düzce Üniversitesi, Fen Bilimleri Enstitüsü, Elektrik-Elektronik ve Bilgisayar Mühendisliği Bölümü, 81620, Düzce \\ ${ }^{3}$ Kocaeli Üniversitesi, Teknoloji Fakültesi, Biyomedikal Mühendisliği Bölümü, 41380, Kocaeli
}

- Geliş tarihi / Received: 28.05 .2020

- Düzeltilerek geliş tarihi / Received in revised form: 07.01 .2021

- Kabul tarihi / Accepted: 13.04.2021

$\ddot{O} z$

Teknolojinin hızlı bir şekilde gelişmesi ile birlikte 3B (üç boyutlu) yazdırma teknolojileri de gerek baskı materyali veya yedek parça çeşitliliği gerekse de yazılım ve uygulama bakımından bu gelişimin bir parçası olarak günlük hayatımızda yerini almaktadır. Mevcut gelişmeler sonucunda uygunlaşan maliyetleri sebebi ile ulaşılabilirliği daha mümkün olan FDM (kaynamış birikim modelleme) teknolojisinin ilk örnek ve hobi olarak kullanımı yaygınlaşmaktadır. Bu çalışmada 3B yazdırma teknolojilerinden biri olan FDM yönteminden yararlanılarak, kullanımı en yaygın materyaller olan ABS (akrilonitril bütadien stiren) ve PLA (polilaktik asit) ile farklı doluluk oranlarına sahip baskısı alınan numunelerin mekanik özellikleri deneysel olarak incelenmiștir. 3B yazdırma teknolojisi ile elde edilen baskıların malzeme türlerine göre kullanılabilirliğine dair çeşitli öneriler sunulmuştur. Bu kapsamda; PLA materyalinin ABS materyaline kıyasla daha yüksek çekme dayanımı sağladığı, ABS materyalinin PLA materyaline kıyasla daha düşük eğilme dayanımı gösterdiği sonucuna varılmıştır.

Anahtar kelimeler: 3B yazdırma, İmalat, İmalat parametreleri, Malzeme

\begin{abstract}
With the rapid development of technology, 3D (three-dimensional) printing technologies also take their place in our daily lives as a part of this development in terms of printing material or spare parts variety, software and application. As a result of current developments, FDM (fused accumulation modeling) technology, which is more accessible due to its lower costs, is becoming widespread as a first example and hobby. In this study, using the FDM method, which is one of the $3 D$ printing technologies, the mechanical properties of the samples printed with different filling ratios with ABS (acrylonitrile butadiene styrene) and PLA (polylactic acid), which are the most common materials to use, were experimentally investigated. Various suggestions are presented regarding the usability of the prints obtained with $3 D$ printing technology according to the material types. In this context; It was concluded that PLA material provides higher tensile strength compared to ABS material, and ABS material has lower flexural strength compared to PLA material.
\end{abstract}

Keywords: 3D printing, Manufacturing, Manufacturing parameters, Material

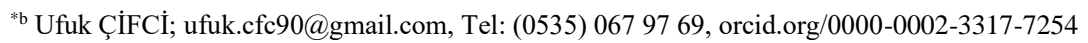

${ }^{a}$ orcid.org/0000-0003-1394-0248_ $\quad{ }^{c}$ orcid.org/0000-0002-1288-6166
} 


\section{Giriş}

Üretim modelinin bir basamağı olan imalat, ürün elde edebilmesi açısından yarı mamulden mamul hale getirme işlemidir. İstenilen amaca uygun olmakla beraber farklı üretim metotları da gelişim göstermektedir (Boyac1, 2010). Eklemeli imalatta alışılmamış imalat yöntemleri olarak bu gelişmelere öncülük etmektedir. Birçok alanda olduğu gibi üretim sektöründe de gelişen teknoloji ve üretim metotları sayesinde ürün geliştirme sürecinin azaldığı gözlemlenmektedir (Durgun, 2015).

Plastik türevleri, polimer, metal ve metal alaşımları, seramik vb. gibi geniş bir yelpaze ile bilgisayar teknolojisi eşliğinde üç boyutlu katı obje üretmeyi mümkün kılan yeni jenerasyon imalat teknolojisinin keşfi 1970'li y1llara kadar uzanmaktadır (Hakan Verdu Martinez vd., 2016). Çok boyutlu yazdırma işlemi ise, dijital ortamda hazırlanan CAD (bilgisayar destekli tasarım) dosyaları kullanılarak belirli işlemler uygulandiktan sonra katı nesneler elde etme sürecidir. Bu işlemleri yapan yazıcıların kullanım alanları çeşitli olup bu yöntemle elde edilen modellerin kisa sürede incelenip değerlendirme yapılmas1 ve tersine mühendislik gerektiren uygulamalarda kullanılması mümkün hale gelmiştir. Günümüzde klasik yöntemler ile işlenmesi zor ve neredeyse imkânsız olan karmaşık yapıya sahip ürünler bu teknoloji sayesinde kolaylıkla oluşturulabilir hale getirilmiştir (Çelik, 2015; Gür, 2017; Korkmaz, 2014; Maden vd., 2016; Rindfleisch vd., 2017).

3B yazıcılar dijital ortamda tasarlanan veya tarama ile elde edilen modelleri plastik, metal, seramik veya biyolojik mürekkep gibi amacına uygun farklı materyaller kullanılarak fiziksel ürünler elde etme teknolojisidir (Rayna vd., 2009; Satyanarayana vd., 2015). Ürün tasarımlarının ve prototiplerinin test etmek amaçlı kullanılabiliyor olması, fabrika sistemlerine gerek duymadan ayrık parçaların talebe uygun üretilebilmesi bu teknolojinin en önemli özelliklerindendir (Yampolskiy vd., 2016).

\section{2. Üç boyutlu yazdırma teknolojileri}

3B yazdırma teknolojilerinde, genellikle materyal düzlemsel bir tabla üzerine katmanlar halinde üst üste yığılır ve böylece baskı işlemi gerçekleştirilmiş olur. Günümüzde pek çok katmanl1 üretim yöntemi geliştirilmiş ve geliştirilmeye devam edilmektedir. SLM (seçici lazer eritme), ya da DMLS (doğrudan metal sinterleme), SLS (seçici lazer sinterleme), FDM gibi bazı yöntemler katmanların üretilmesi için malzemeyi eritirken ya da yumuşatırken, diğer metotlar SLA (stereolitografi cihaz1) gibi farkl1 gelişmiş teknolojileri kullanarak reçine gibi sıvı malzemeleri noktasal şekilde sertleştirerek birbirleri ile birleştirmektedir (Aydın, 2014; Campbell vd., 2012; Çifci vd., 2018a; Huang vd., 2013).

Eklemeli imalatta, öncelikli olarak bir üç boyutlu model dosyası yaratılmakta, daha sonra bu modelin üretilebilmesi için gerekli takım yolları uygun bilgisayar yazılımı ile oluşturulmaktadır. Yazılım sayesinde, STL (stereolitografi) adı verilen bir kod oluşturulmaktadır. Sonrasında, tercih edilen üretim yöntemi esas alınıp, uygun cihaz seçilerek ve parametreler oluşturularak, üretim yapılmaktadır (Çelik vd., 2017; Novakova-Marcincinova vd., 2012; Wong vd., 2012).

Prototip üretim süreci sırasında uygulanmas1 gereken adımlar Şekil l'de gösterildiği gibidir.

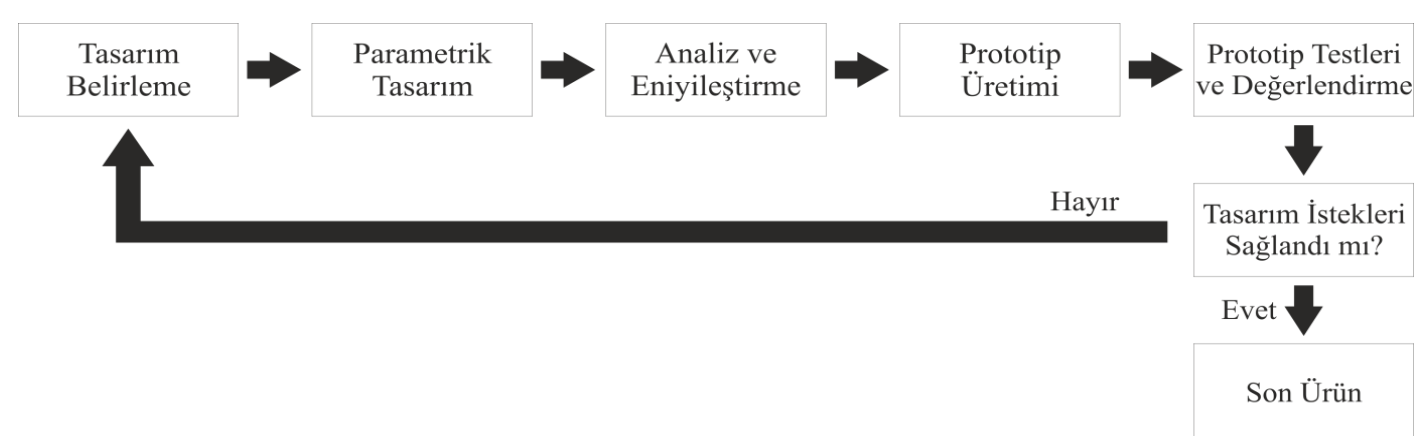

Şekil 1. Prototip üretim süreci (Ekici vd., 2009)

3B yazdırma teknolojilerine ait yöntemler uygulaması yapılacak sektör göz önünde bulundurularak tercih edilmelidir. FDM yöntemi diğer yöntemlere kıyasla yedek parça maliyetlerinin uygun ve ulaşılabilir olması sebebi ile hobi amaçlı kullanıcılar tarafından en çok tercih edilen 3B yazdırma teknolojisi olarak göze çarpmaktadır (Arı, 2016; Çifci vd., 2018b; Kun, 2016). 


\subsection{FDM teknolojisi}

$\mathrm{Bu}$ teknoloji kâğıt, balmumu, reçine, seramik, plastik, termoplastik, çikolata, metal ve alaşımları vb. materyaller ile kullanıma uygun ve uygulanabilirliği açısından diğer teknolojilere nazaran daha kolay bir yöntemdir. Elde edilmek istenen kat1 model filament ad1 verilen bask1 materyalinin $\mathrm{x}, \mathrm{y}$ ve $\mathrm{z}$ eksenlerinde hareket eden pirinç, alüminyum vb. 1sıtıcı uç yardımı ile eritilmesi neticesinde elde edilir (Berman, 2012;
Çifci vd., 2019a; Güneş, 2018; Wong vd., 2014). Yazdırma esnasında gerektiği durumlarda destek yapıları da oluşturulabilir.

FDM teknolojisi kullanan 3B yazıcılar tip olarak Kartezyen, corexy ve delta tipi olmak üzere üçe ayrılır. Her birinin yapısal tasarımı farklılık göstermesine rağmen üretim sürecinde uyguladığı işlemler aynıdır. FDM teknolojisinin yazdırma işlemi Şekil 2'de gösterildiği gibidir.

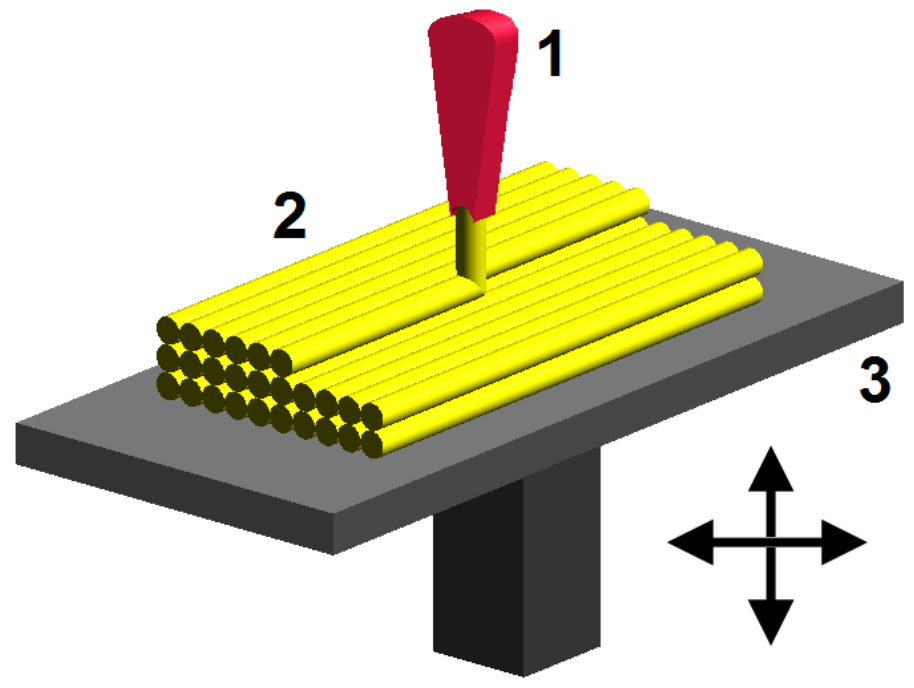

Şekil 2. FDM teknolojisi yazdırma işlemi (Zureks, 2008)

$\mathrm{Bu}$ teknolojinin en önemli özelliği ise karmaşık yapıya sahip gerek iç içe sarmal gerek ince işlemeli tasarımlarda kullanıcıya imalat imkânı sağlamasıdır. Baskısı alınacak geometrik modelin karmaşık yapısının hiçbir önemi olmamakla beraber bu teknoloji tüm tasarımları tek parça halinde yazdırma özelliğine sahiptir (Çifci vd., 2019b).

\section{Materyal ve yöntem}

Deneyler kapsaminda tercih edilen materyal ve uygulanan yöntemler çalışmanın bu kısmında belirtildiği gibidir.

\subsection{Materyal}

\subsection{1. Çalışmada kullanılan üç boyutlu yazıcı}

Deneyler kapsamında oluşturulan numuneler FDM teknolojisi kullanan Kartezyen tipi 3B yazıci ile elde edilmiştir. Tamamen Türk tasarımı olan bu yazıcı, açık kaynaklı ve patentli, FDM tipi 3B yazıcidır.

Çalışmada kullanılan çok boyutlu yazıcı Şekil 3'te gösterildiği gibidir.

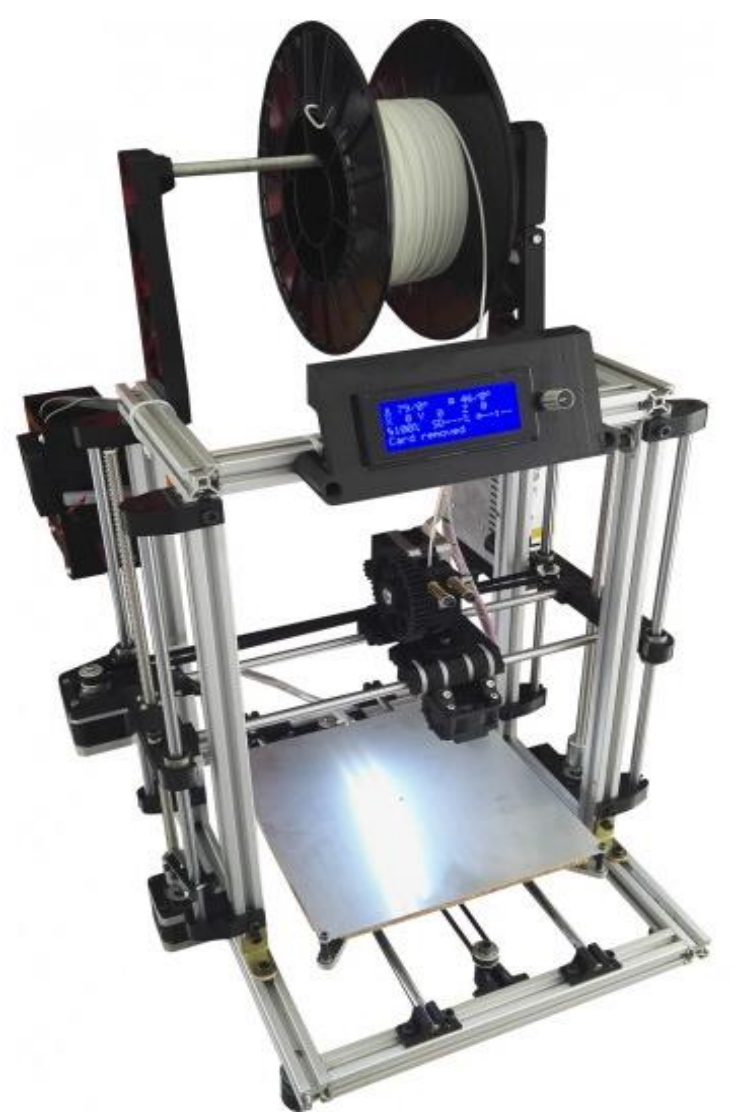

Şekil 3. Çalışmada kullanılan çok boyutlu yazıcı (Kalmaz, 2020) 


\subsection{2. Çalışmada kullanılan baskı materyalleri}

Bu çalışmada FDM teknolojisi ile kullanımı en yaygin olan ABS ve PLA materyalleri ile numunelerin baskıları alınmıştır.
ABS materyali termoplastik özelliğe sahip olup strese karşı ortalama bir direnç gösteren rijit bir yapısı vardır. Genel olarak ergime sıcaklığ $1210^{\circ} \mathrm{C}$ $250^{\circ} \mathrm{C}$ aralığındadır. Deneylerde kullanılan ABS materyalinin fiziksel ve mekanik özellikleri Tablo 1'de gösterildiği gibidir (Kuzu Demir vd., 2016; Olivera vd., 2016).

Tablo 1. Deneylerde kullanılan ABS materyalinin fiziksel ve mekanik özellikleri (Sigma3D, 2020a)

\begin{tabular}{lllll}
\hline Özellikler & Test Koşulu & Test Metodu & Birim & Tipik Değer \\
\hline Özgül Ağırlık & & D792 & $\mathrm{g} / \mathrm{cm}^{3}$ & 1.032 \\
Çekme Mukavemeti & $2 \mathrm{~mm} / \mathrm{dk}$ & $\mathrm{D} 638$ & $\mathrm{MPa}$ & 10.4 \\
Elastik Modülü & $2 \mathrm{~mm} / \mathrm{dk}$ & $\mathrm{D} 638$ & $\mathrm{GPa}$ & 0.80 \\
Eğme Mukavemeti & $1.15 \mathrm{~mm} / \mathrm{dk}$ & $\mathrm{D} 790$ & $\mathrm{MPa}$ & 43.05 \\
Eğme Modülü & $1.15 \mathrm{~mm} / \mathrm{dk}$ & $\mathrm{D} 790$ & $\mathrm{GPa}$ & 2.18 \\
İzod Darbe Dayanımı & & $\mathrm{D} 256$ & $\mathrm{~kJ} / \mathrm{m}^{2}$ & 30.45 \\
Geçiş Sicaklı̆̆ Tayini & & $\mathrm{D} 3418$ & ${ }^{\circ} \mathrm{C}$ & $100.59-100.08$ \\
Isıl Defleksiyon & & D648 & ${ }^{\circ} \mathrm{C}$ & $64.3-61.0$ \\
Shore D Sertlik & & D2240 & & $78.0-89.5$ \\
Erime Akış Hızı & $190^{\circ} \mathrm{C} / 2.16 \mathrm{~kg}$ & $\mathrm{D} 1238$ & $\mathrm{~g} / 10 \mathrm{dk}$ & $4.31 \mathrm{AB}$ \\
\hline
\end{tabular}

PLA materyali ergime sıcaklığı ve kopma uzaması özellikleri bakımından dezavantajlı olup, boyutsal kararlılığı ve baskı sırasında sağladığı kolaylık bakımından avantaj sağlamaktadır. Ergime sıcaklığ $170^{\circ} \mathrm{C}-220^{\circ} \mathrm{C}$ aralığındadır. Deneylerde kullanılan PLA materyalinin fiziksel ve mekanik özellikleri Tablo 2'de gösterildiği gibidir (Madhavan Nampoothiri vd., 2010; Murariu vd., 2014).

Tablo 2. Deneylerde kullanılan PLA materyalinin fiziksel ve mekanik özellikleri (Sigma3D, 2020b)

\begin{tabular}{lccc}
\hline \multicolumn{1}{c}{ Özellikler } & Test Metodu & Birim & Tipik Değer \\
\hline Özgül Ağırlık & $\mathrm{D} 792$ & $\mathrm{~g} / \mathrm{cc}$ & 1.24 \\
Erime Akış Hızı & $\mathrm{D} 1238$ & $\mathrm{~g} / 10 \mathrm{dk}$ & $6\left(210^{\circ} \mathrm{C} / 2.16 \mathrm{~kg}\right)$ \\
Bağ1l Viskozite & $\mathrm{D} 5225$ & & 4 \\
Erime Sıcaklı̆̆ı & $\mathrm{D} 3418$ & ${ }^{\circ} \mathrm{C}$ & $145^{\circ}-160^{\circ}$ \\
Geçiş Sıcaklığı Tayini & $\mathrm{D} 3418$ & $\mathrm{C}$ & $55^{\circ}-60^{\circ}$ \\
Gerilme Dayanım Gücü & $\mathrm{D} 882$ & $\mathrm{MPa}$ & 60 \\
Kopmada Çekme Dayanımı & $\mathrm{D} 882$ & $\mathrm{MPa}$ & 53 \\
Çekme Uzaması & $\mathrm{D} 256$ & $\mathrm{~kJ} / \mathrm{m}^{2}$ & 6 \\
İzod Darbe Dayanımı & $\mathrm{D} 256$ & $\mathrm{MPa}$ & 16 \\
Eğme Mukavemeti & $\mathrm{D} 790$ & $\mathrm{MPa}$ & 83 \\
Eğme Modulü & $\mathrm{D} 790$ & & 3.8 \\
Isıl Defleksiyon & $\mathrm{E} 2092$ & $\mathrm{C}$ & 55 \\
\hline
\end{tabular}

\subsection{Yöntem}

$\mathrm{Bu}$ çalışmada 3B yazdırma teknolojisi ile baskısı alınan farklı doluluk oranlarına sahip numuneler üzerinde çekme mukavemeti ve eğme mukavemeti deneyleri gerçekleştirilmiştir. Uygulamalara ait deneysel tasarım çizelgesi Tablo 3 'te gösterildiği gibidir.

Tablo 3. Uygulamalara ait deneysel tasarım çizelgesi

\begin{tabular}{|c|c|c|c|c|c|c|c|}
\hline \multirow{4}{*}{$\begin{array}{l}\text { Materyal } \\
\text { Türü }\end{array}$} & \multicolumn{6}{|c|}{ DENEY TÜRÜ } & \multirow{4}{*}{ Toplam } \\
\hline & \multicolumn{3}{|c|}{ Çekme Mukavemeti } & \multicolumn{3}{|c|}{ Ĕgme Mukavemeti } & \\
\hline & \multicolumn{6}{|c|}{ Doluluk Oranı } & \\
\hline & $\% 20$ & $\% 40$ & $\% 60$ & $\% 20$ & $\% 40$ & $\% 60$ & \\
\hline ABS & 3 & 3 & 3 & 3 & 3 & 3 & 18 \\
\hline PLA & 3 & 3 & 3 & 3 & 3 & 3 & 18 \\
\hline Toplam & 6 & 6 & 6 & 6 & 6 & 6 & 36 \\
\hline
\end{tabular}


Çekme mukavemeti ve eğme mukavemeti deneyleri için numune boyutları yaygın olarak kullanılan ASTM D638 ve ASTM D790 standartları baz alınarak tasarlanmıştır (ASTM International, 2021).

Baskısı alınan numunelerin yazdırma parametreleri kullanılan materyalin cinsi, markası, ortam koşulları ve kullanılan 3B yazıcının özelliklerine göre değişiklik gösterebilmektedir. Parametreleri uygun koşullarda belirlemek için en iyi yöntem kalibrasyon için özel olarak tasarlanmış CAD dosyalarının yazdırılması ile tayin edilir. $\mathrm{Bu}$ çalışmada baskısı alınan numunelerin yazdırma parametreleri Tablo 4'te gösterildiği gibidir.

Tablo 4. Baskısı alınan numunelerin yazdırma parametreleri (Bekar, 2020)

\begin{tabular}{lccc}
\hline \multicolumn{1}{c}{ Parametre } & Birim & ABS & PLA \\
\hline Filament Çapı1 & $\mathrm{mm}$ & 1,75 & 1,75 \\
Nozul Çap1 & $\mathrm{mm}$ & 0,4 & 0,4 \\
Katman Yüksekliği & $\mathrm{mm}$ & 0,3 & 0,3 \\
Başlangıç Nozul Sıcaklı̆̆1 & ${ }^{\circ} \mathrm{C}$ & 220 & 210 \\
Nozul Sıcaklı̆̆1 & ${ }^{\circ} \mathrm{C}$ & 210 & 190 \\
Tabla Sıcaklığ1 & ${ }^{\circ} \mathrm{C}$ & 90 & 60 \\
Başlangıç Baskı Hızı & $\mathrm{mm} / \mathrm{s}$ & 15 & 15 \\
Baskı Hızı & $\mathrm{mm} / \mathrm{s}$ & 50 & 50 \\
Parça Soğutma Fanı & $\%$ & 50 & 100 \\
Alt Duvar Sayısı & & 3 & 3 \\
Üst Duvar Sayısı & & 3 & 3 \\
Anahat/Çevre Duvar Sayısı & & 2 & 2 \\
\hline
\end{tabular}

\subsubsection{Deney numunelerinin tayini}

Çekme mukavemeti ve eğme mukavemeti deneyleri için tüm numuneler $300 \mu \mathrm{m}$ katman kalınlığı ile yazdırılmıştır. Çekme mukavemeti deneyi numunesine ait teknik resim Şekil 4 (a), eğme mukavemeti deneyi numunesine ait teknik resim Şekil 4'te gösterildiği gibidir (Kartal, 2017).

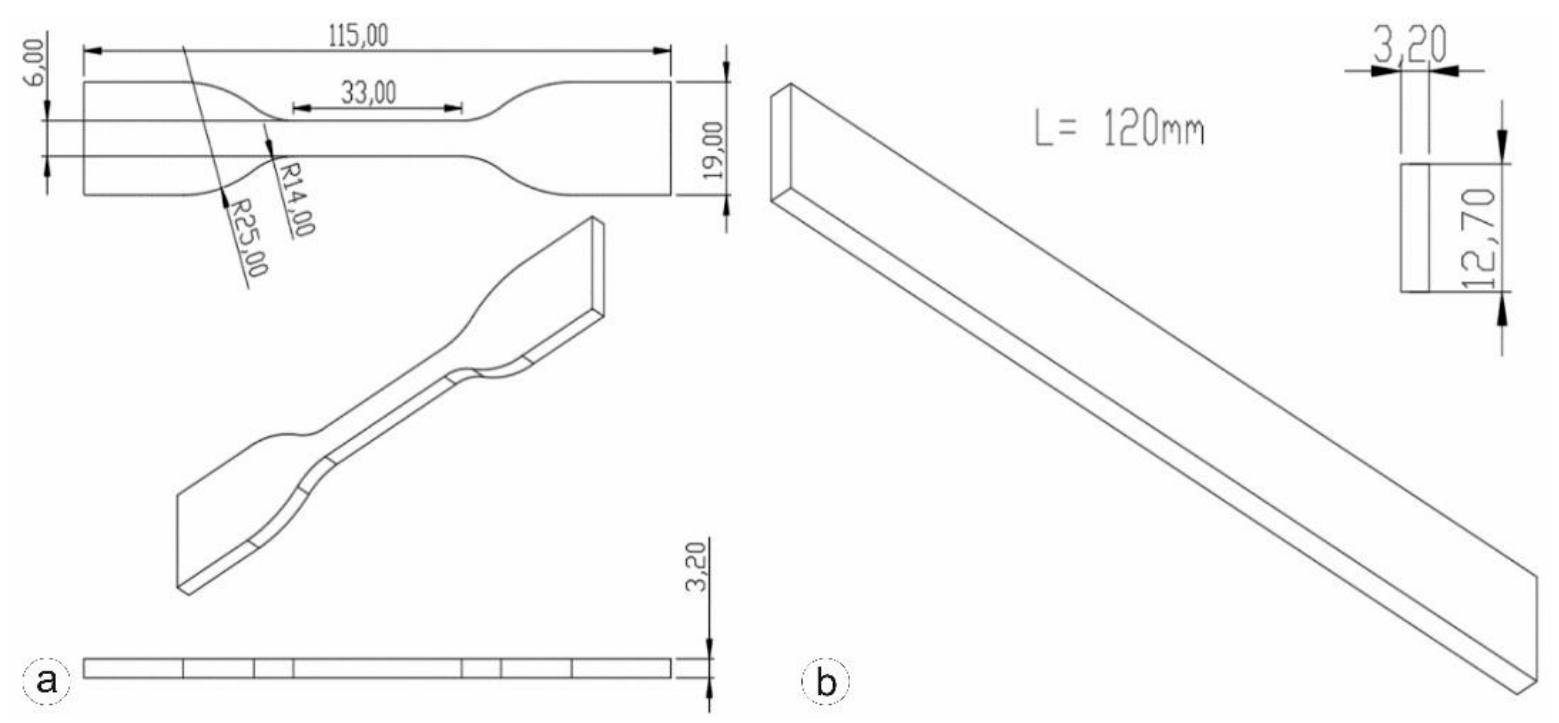

Şekil 4. (a) Çekme deneyi numunesi ve (b) Eğme deneyi numunesi teknik resmi

\section{Bulgular ve tartışma}

Deneyler kapsamında elde edilen sonuçlar çalışmanın bu kısmında belirtildiği gibidir.

\section{1. Çekme mukavemeti deneyi bulguları}

Farklı doluluk oranlarına sahip ABS materyali ile baskısı alınan numunelerin çekme mukavemeti deneyi sonuçları Tablo 5 'te gösterildiği gibidir. 
Tablo 5. ABS materyali ile baskısı alınan numunelerin çekme mukavemeti deneyi sonuçları

\begin{tabular}{|c|c|c|c|}
\hline $\begin{array}{c}\text { Doluluk Oranı } \\
(\%)\end{array}$ & $\begin{array}{c}\text { Çekme Mukavemeti } \\
(M P a)\end{array}$ & $\begin{array}{c}\text { Elastik Modül } \\
(G P a)\end{array}$ & $\begin{array}{c}\text { Kopmadaki Uzama } \\
(\%) \\
\end{array}$ \\
\hline \multirow{3}{*}{20} & 22.5 & 1.32 & 10.06 \\
\hline & 21.6 & 1.23 & 15.93 \\
\hline & 21.7 & 1.25 & 7.63 \\
\hline Ortalama & 21,93 & 1,26 & 11,20 \\
\hline \multirow{3}{*}{40} & 22.4 & 1.36 & 11.66 \\
\hline & 22.6 & 1.34 & 15.23 \\
\hline & 21.8 & 1.27 & 10.76 \\
\hline Ortalama & 22,26 & 1,32 & 12,55 \\
\hline \multirow{3}{*}{60} & 23.7 & 1.26 & 11.68 \\
\hline & 24.5 & 1.33 & 16.27 \\
\hline & 25 & 1.37 & 16.89 \\
\hline Ortalama & 24,4 & 1.32 & 14,94 \\
\hline
\end{tabular}

Farklı doluluk oranlarına sahip PLA materyali ile baskısı alınan numunelerin çekme mukavemeti deneyi sonuçları Tablo 6'da gösterildiği gibidir.

Tablo 6. PLA materyali ile baskısı alınan numunelerin çekme mukavemeti deneyi sonuçları

\begin{tabular}{|c|c|c|c|}
\hline $\begin{array}{c}\text { Doluluk Oranı } \\
(\%)\end{array}$ & $\begin{array}{c}\text { Çekme Mukavemeti } \\
(M P a)\end{array}$ & $\begin{array}{c}\text { Elastik Modül } \\
(G p a)\end{array}$ & $\begin{array}{c}\text { Kopmadaki Uzama } \\
(\%)\end{array}$ \\
\hline \multirow{3}{*}{20} & 42.5 & 1.97 & 1.53 \\
\hline & 42 & 2.05 & 1.7 \\
\hline & 42.8 & 2.2 & 4.66 \\
\hline Ortalama & 42,43 & 2,07 & 2,63 \\
\hline \multirow{3}{*}{40} & 42.9 & 2.48 & 3.32 \\
\hline & 43.3 & 2.31 & 3.42 \\
\hline & 44.4 & 2.86 & 2.47 \\
\hline Ortalama & 43,53 & 2,55 & 3,07 \\
\hline \multirow{3}{*}{60} & 48 & 2.36 & 2.37 \\
\hline & 46.1 & 2.58 & 4.71 \\
\hline & 47.9 & 2.52 & 4.4 \\
\hline Ortalama & 47,33 & 2,48 & 3,82 \\
\hline
\end{tabular}

ABS materyali ile baskısı alınan numunelerin çekme mukavemeti deneyi sonrası görüntüleri doluluk oranlarına göre Şekil 5'te gösterildiği gibidir. 

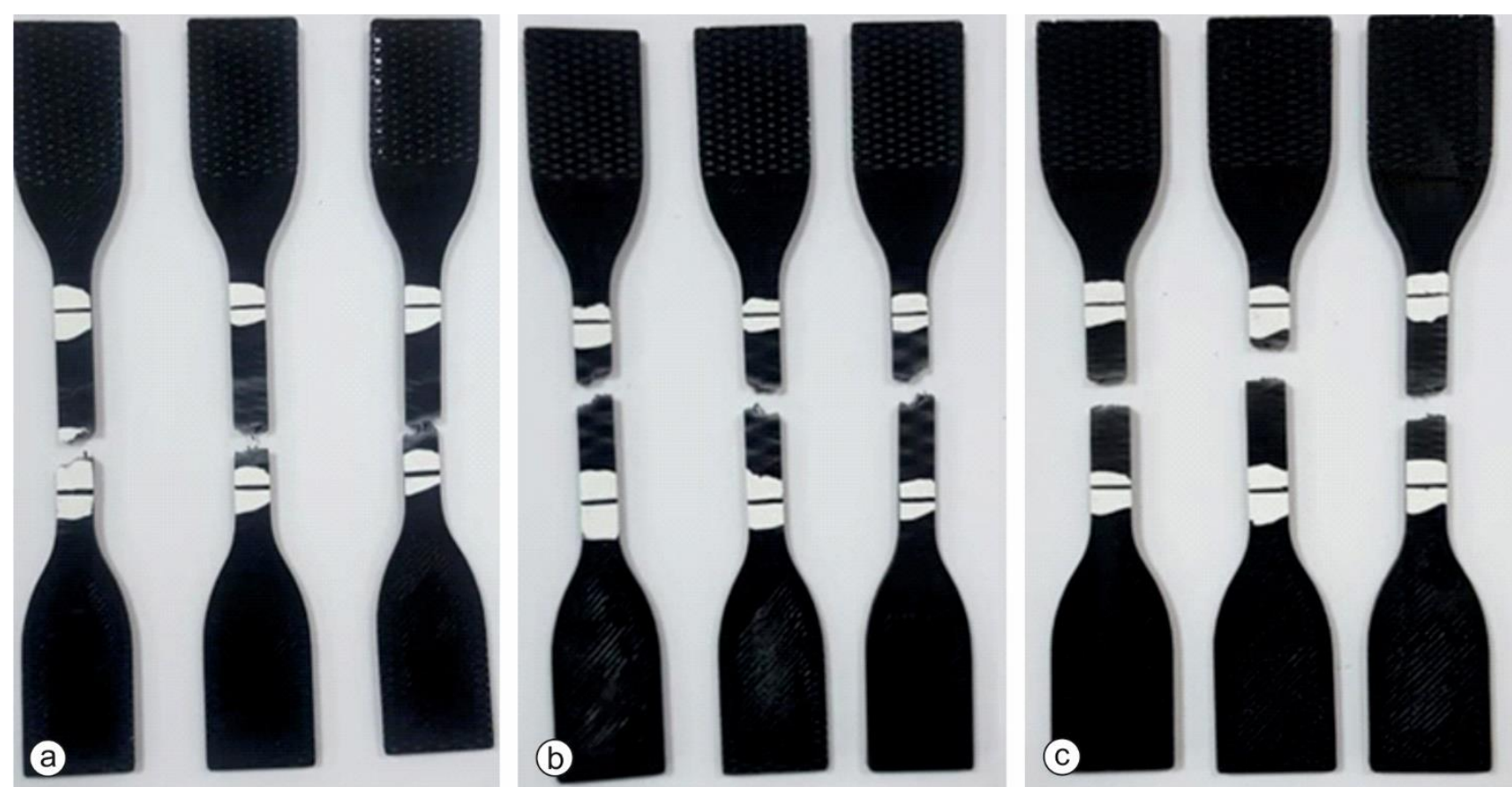

Şekil 5. ABS materyali ile baskısı alınan numunelerin çekme mukavemeti deneyi sonrası görüntüleri doluluk oranlarına göre (a) \%20, (b) \%40 ve (c) \%60

PLA materyali ile baskısı alınan numunelerin çekme mukavemeti deneyi sonrası görüntüleri doluluk oranlarına göre Şekil 6'da gösterildiği gibidir.
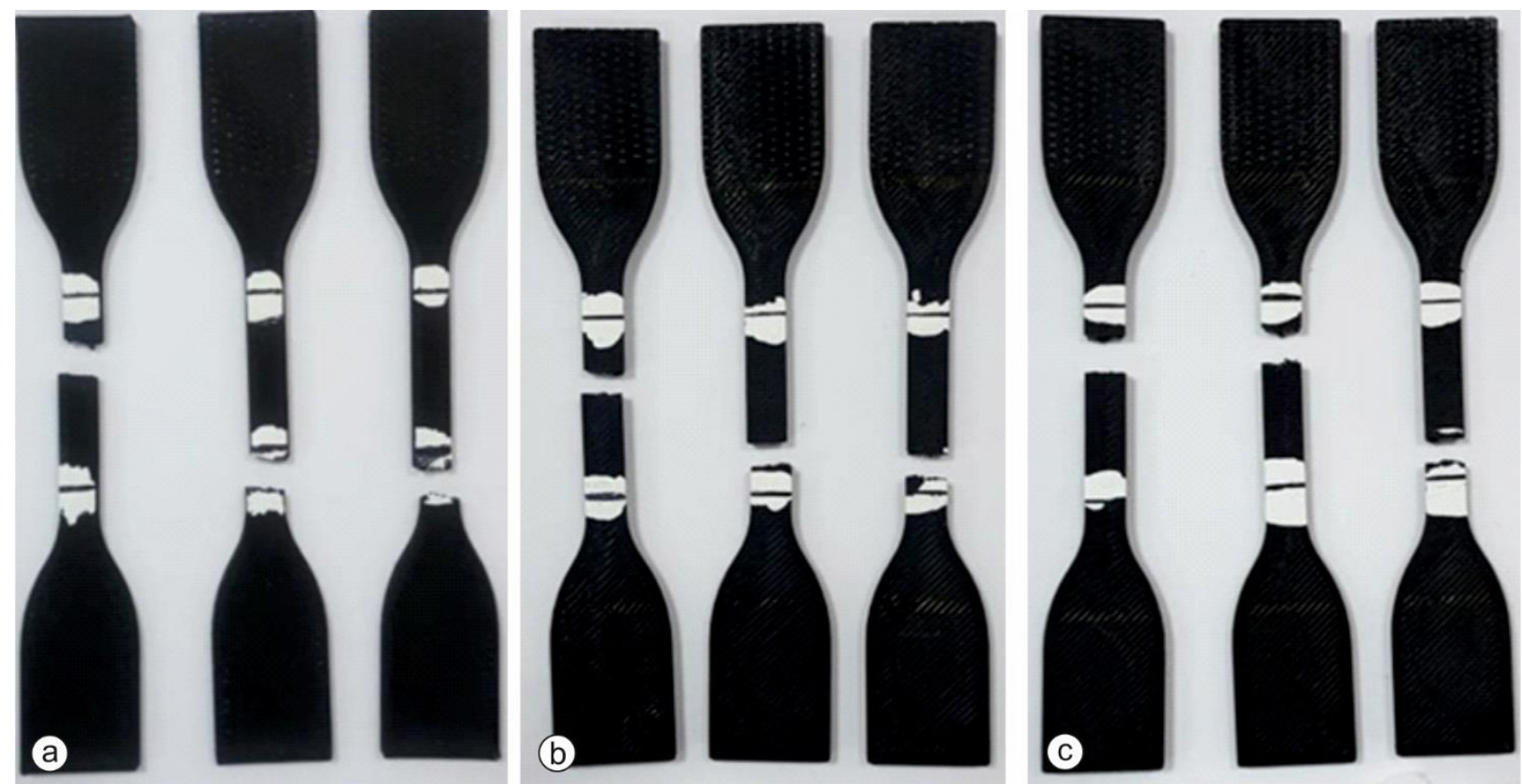

Şekil 6. PLA materyali ile baskısı alınan numunelerin çekme mukavemeti deneyi sonrası görüntüleri doluluk oranlarına göre (a) $\% 20$, (b) $\% 40$ ve (c) $\% 60$

\section{2. Ĕgme mukavemeti deneyi bulguları}

Farklı doluluk oranlarına sahip ABS ve PLA materyalleri ile baskısı alınan numunelerin eğme mukavemeti deneyi sonuçları Tablo 7'de gösterildiği gibidir. 
Tablo 7. Farklı doluluk oranlarına sahip ABS ve PLA materyalleri ile baskısı alınan numunelerin eğme mukavemeti deneyi sonuçları

\begin{tabular}{ccc}
\hline \multirow{2}{*}{$\begin{array}{c}\text { Doluluk Oranı } \\
(\%)\end{array}$} & \multicolumn{2}{c}{ Materyal } \\
\cline { 2 - 3 } & $\begin{array}{c}\text { ABS } \\
(M P a)\end{array}$ & $\begin{array}{c}\text { PLA } \\
(M P a)\end{array}$ \\
\hline \multirow{2}{*}{$\mathbf{2 0}$} & 30.37 & 63.86 \\
\cline { 2 - 3 } & 29.92 & 61.86 \\
\cline { 2 - 3 } Ortalama & 29.55 & 64.03 \\
\hline \multirow{2}{*}{$\mathbf{4 0}$} & $\mathbf{2 9 , 9 4}$ & $\mathbf{6 3 , 2 5}$ \\
\hline & 30.26 & 62.68 \\
\hline Ortalama & 29.29 & 64.54 \\
\hline \multirow{2}{*}{$\mathbf{6 0}$} & 28.69 & 62.33 \\
\hline & $\mathbf{2 9 , 4 1}$ & $\mathbf{6 3 , 1 8}$ \\
\hline & 34.42 & 66.9 \\
\hline Ortalama & 34.85 & 64.24 \\
\hline
\end{tabular}

ABS materyali ile baskısı alınan numunelerin eğme mukavemeti deneyi sonrası görüntüleri doluluk oranlarına göre Şekil 7'de gösterildiği gibidir.
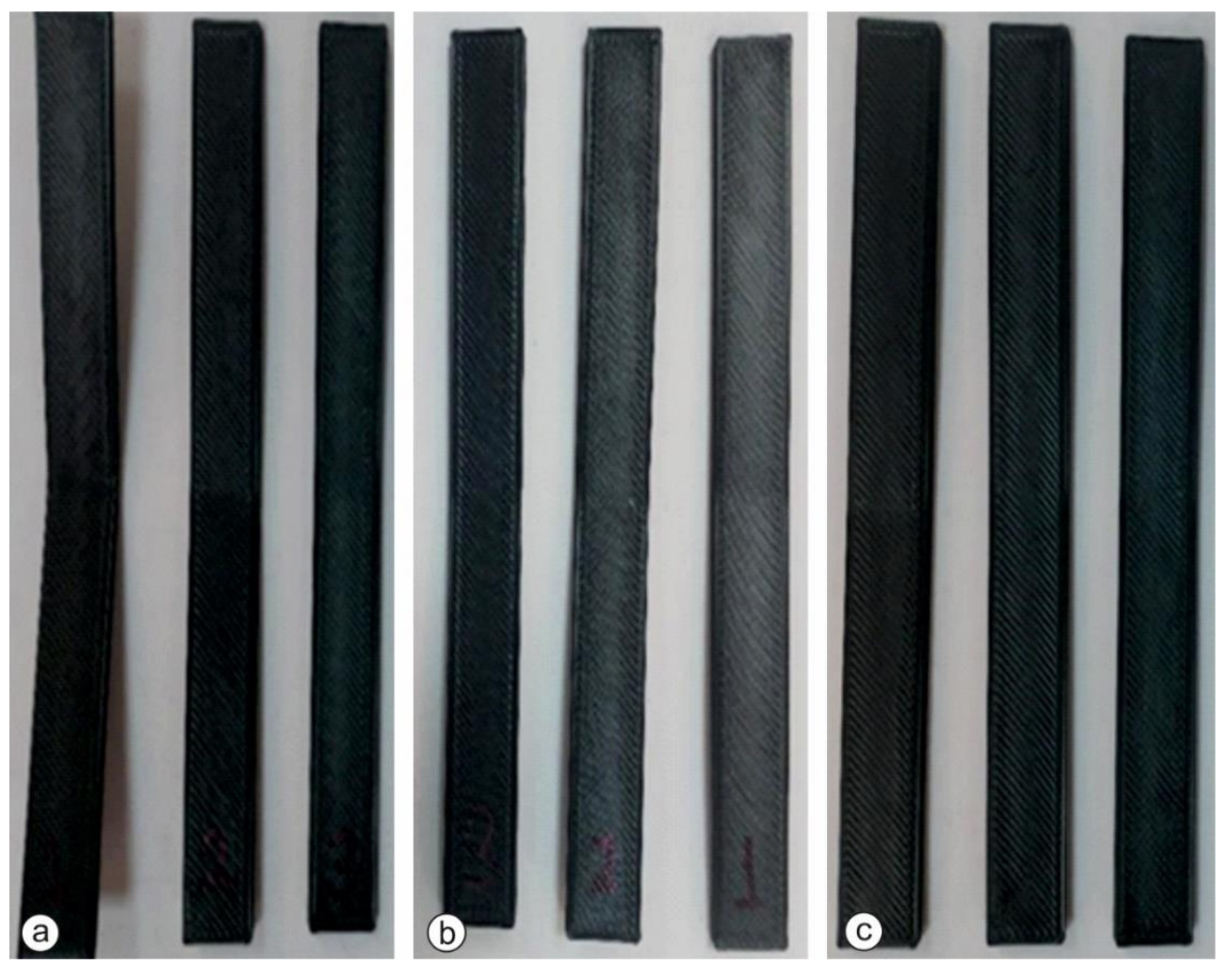

Şekil 7. ABS materyali ile baskısı alınan numunelerin eğme mukavemeti deneyi sonrası görüntüleri doluluk oranlarına göre (a) \%20, (b) \%40 ve (c) \%60

PLA materyali ile baskısı alınan numunelerin eğme mukavemeti deneyi sonrası görüntüleri doluluk oranlarına göre Şekil 8'de gösterildiği gibidir. 

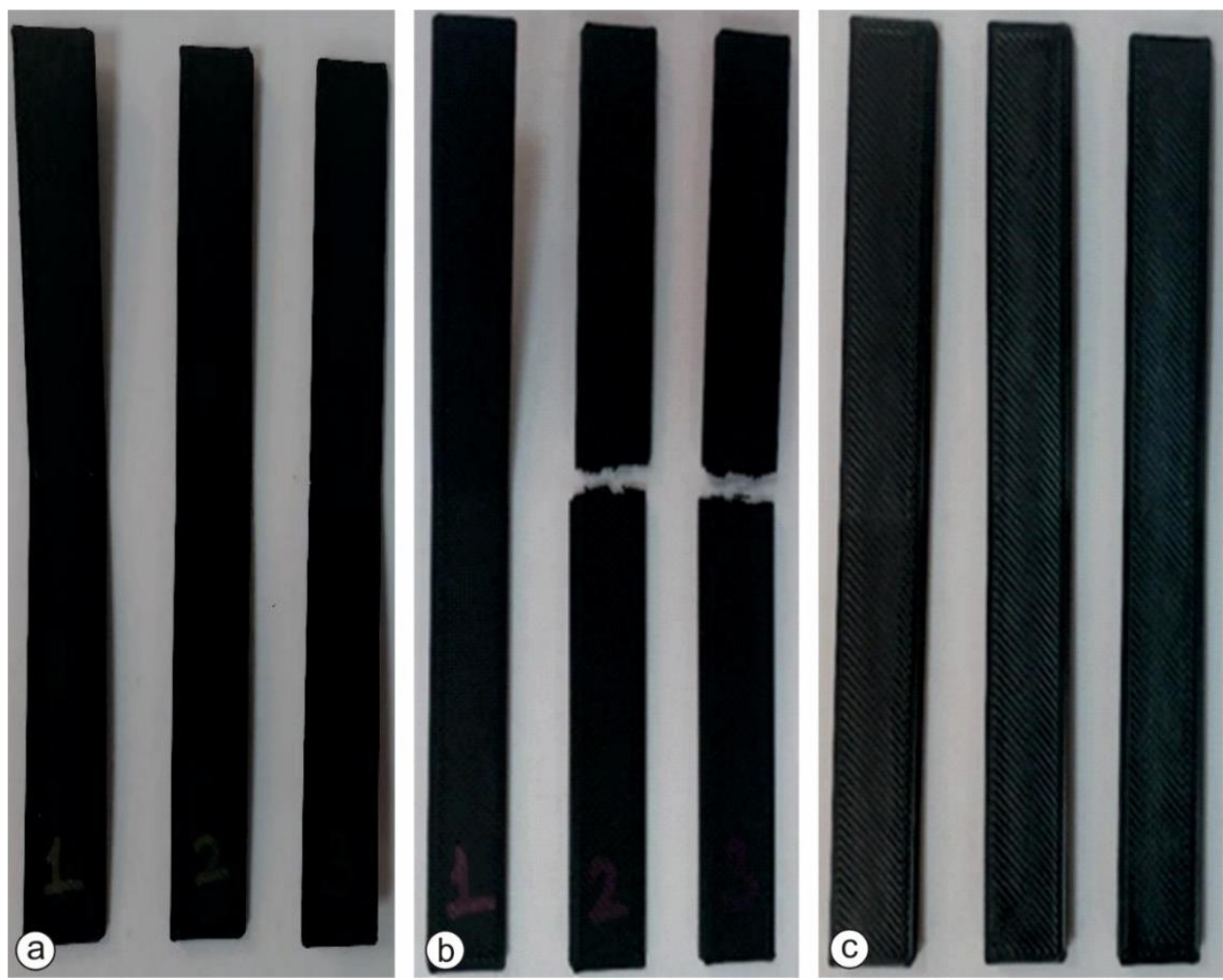

Şekil 8. PLA materyali ile baskısı alınan numunelerin eğme mukavemeti deneyi sonrası görüntüleri doluluk oranlarına göre (a) \%20, (b) \%40 ve (c) $\% 60$

\section{Tartışma ve Sonuçlar}

Çalışmada yapılmış olan deneyler sonucunda elde edilen verilere ait açıklayıcı istatistikler bu bölümde incelenmiştir.

Yapılan çalışmalar kapsamında çekme mukavemeti deneylerinde;

- ABS materyal ile \%20 doluluk oranında baskısı alınan numunelerde ortalama çekme mukavemeti değeri 21,93 $\mathrm{MPa}$, kopmadaki uzamanın ise $\% 11,2$ olduğu,

- PLA materyal ile \%20 doluluk oranında baskısı alınan numunelerde ortalama çekme mukavemeti değeri 42,43 MPa, kopmadaki uzamanın ise \%2,63 olduğu,

- ABS materyal ile \%40 doluluk oranında baskısı alınan numunelerde ortalama çekme mukavemeti değeri 22,26 MPa, kopmadaki uzamanın ise $\% 12,55$ olduğu,

- PLA materyal ile \%40 doluluk oranında baskısı alınan numunelerde ortalama çekme mukavemeti değeri 43,53 $\mathrm{MPa}$, kopmadaki uzamanın ise $\% 3,07$ olduğu,
- ABS materyal ile \%60 doluluk oranında baskıs1 alınan numunelerde ortalama çekme mukavemeti değeri 24,4 $\mathrm{MPa}$, kopmadaki uzamanın ise $\% 14,94$ olduğu,

- PLA materyal ile \%60 doluluk oranında baskısı alınan numunelerde ortalama çekme mukavemeti değeri 47,33 $\mathrm{MPa}$, kopmadaki uzamanın ise $\% 3,82$ olduğu,

- ABS ve PLA materyal ile baskısı alınan numunelerde doluluk oranı arttıkça az da olsa çekme mukavemeti ve kopma uzamasındaki değerlerinde doğru oranda arttığ 1 ,

- Baskısı alınan numunelerde tüm doluluk oranları temel alındığında ortalama çekme mukavemeti değeri ABS materyalde 24,40 $\mathrm{MPa}$, PLA materyalde ise 47,33 MPa olduğu,

- Baskısı alınan numunelerde tüm doluluk oranları temel alındığında ortalama kopmadaki uzamanın ABS materyalde \%12,9, PLA materyalde ise $\% 3,17$ olduğu,

- PLA materyallerin ABS materyallerine göre bütün doluluk oranlarında daha iyi çekme dayanımı sağladığı, fakat PLA materyallerin 
ABS materyallerine göre daha düşük elastikiyet gösterdiği,

sonuçları elde edilmiştir.

Yapılan çalışmalar kapsamında eğme mukavemeti deneylerinde;

- Baskısı alınan numunelerde \%20 doluluk oranları baz alındığında ortalama eğme mukavemeti değeri ABS materyalde 29,94 MPa, PLA materyalde $63,25 \mathrm{MPa}$ olduğu,

- Baskisı alınan numunelerde \%40 doluluk oranları baz alındığında ortalama eğme mukavemeti değeri ABS materyalde 29,41 $\mathrm{MPa}$, PLA materyalde $63,18 \mathrm{MPa}$ olduğu,

- Baskisı alınan numunelerde \%60 doluluk oranları baz alındığında ortalama eğme mukavemeti değeri ABS materyalde 34,91 MPa, PLA materyalde 66,01 MPa olduğu,

- Baskısı alınan numunelerde tüm doluluk oranları baz alındığında ortalama eğme mukavemeti değeri ABS materyalde 31,42 MPa, PLA materyalde $64,15 \mathrm{MPa}$ olduğu,

- ABS ve PLA materyal ile baskısı alınan numunelerde doluluk oranı arttıkça eğme mukavemetinin de doğru oranda artmadığı bu oranların $\% 40$ doluluk oranında ortaya çıktığı, fakat $\% 60$ doluluk oranının her iki materyalde de en yüksek eğme mukavemetine sahip olduğu,

- Ortalama eğme mukavemeti değerleri karşılaştırıldığında PLA materyalin ABS materyale göre daha iyi eğme dayanımı sağladığı,

sonuçları elde edilmiştir.

Çalışma kapsamında gerçekleştirilen deneyler sonucunda PLA materyalinin ABS materyaline kıyasla daha yüksek çekme dayanımı ve eğme mukavemeti sağladığ 1 , PLA materyalinin ABS materyaline kıyasla düşük uzama katsayısına sahip olup daha kırılgan bir yapıda olduğu sonucuna varılmıştır. Baskısı alınan materyalin markası, 3B yazdırma işleminin gerçekleştiği ortam koşulları ve kullanılan 3B yazıcının özelliklerine göre sonuçlarda çıkan değerler değişiklik gösterecektir. $\mathrm{Bu}$ çalışmada en ideal ortam koşulları ve baskı parametreleri seçilmiştir. Üretilecek ürünlerin uygulama esnasında kullanımına istinaden gerekli şartlar sağlandığı takdirde bu çalışmadaki deney sonuçları dikkate alınarak malzeme seçimi yapılması önerilmektedir.

\section{Kaynaklar}

Arı, A. (2016). Beş parmaklı protez robot el. Yüksek Lisans Tezi, Karadeniz Teknik Üniversitesi Fen Bilimleri Enstitüsü, Trabzon.

ASTM International: Standards and Publications. (2020, 05 January). Acsess adress

https://www.astm.org/Standard/standards-andpublications.html.

Aydın, L. (2014). Üç boyutlu yazıcıyla ayak bileği ortezinin tasarımı ve geliştirilmesi. Yüksek Lisans Tezi, Kocaeli Üniversitesi Fen Bilimleri Enstitüsü, Kocaeli.

Bekar, K., Çifci, U. ve Özkan, A. (2020). 3D yazdırma teknolojileri ile farklı parametre ve materyaller ile baskısı alınan numunelerin çekme dayanımı üzerine etkisi: Literatür araştırması. International Marmara Sciences Congress (Spring 2020) (ss. 778-787). Kocaeli.

Berman, B. (2012). 3-D printing: The new industrial revolution. Business Horizons, 55(2), 155-162. https://doi.org/10.1016/j.bushor.2011.11.003

Boyacı, N. (2010). İmalat için tasarım ve temel kurallarının incelenmesi. Yüksek Lisans Tezi, Gebze Yüksek Teknoloji Enstitüsü Mühendislik ve Fen Bilimleri Enstitüsü, Gebze.

Campbell, I., Bourell, D. and Gibson, I. (2012). addvite manufacturing rapid prototyping comes of age. Rapid Prototyping Journal, 18(4), 255-258. https://doi.org/10.1108/13552541211231563

Çelik, D. (2015). Üç boyutlu yazıcı tasarımı, prototipi ve tersine mühendislik uygulamaları. Yüksek Lisans Tezi, Karabük Üniversitesi Fen Bilimleri Enstitüsü, Karabük.

Çelik, K. ve Özkan, A. (2017). Eklemeli imalat yöntemleri ile üretim ve onarım uygulamaları. Düzce Üniversitesi Bilim ve Teknoloji Dergisi, 5(1), 107-121.

Çifci, U., Özkan, A. ve Akgül, İ. (2018). Üç boyutlu tasarım ve imalat teknolojilerinin imalat için tasarıma olan etkilerinin incelenmesi. 3rd International Congress on 3D Printing (Additive Manufacturing) Technologies and Digital Industry (ss. 486-493). Antalya.

Çifci, U., Özkan, A. ve Akgül, İ. (2019). Üç boyutlu yazdırma teknolojilerinin maliyet ve destek malzemesi gereksinimleri yönünden kıyaslanması ve imalat sektöründe uygulanabilirliği. 4th International Congress on 3d Printing (Additive Manufacturing) 
Technologies and Digital Industry (ss. 482-488). Antalya.

Çifci, U., Özkan, A. ve Taşdemirci, Ç. (2019). Üç boyutlu yazıcı teknolojilerinin hizlı prototip uygulamaları için farklı materyaller aracılığıyla yüzey pürüzlülügüüne etkilerinin incelenmesi. Düzce Üniversitesi Bilim ve Teknoloji Dergisi, 7(3), 1627-1643. https://doi.org/10.29130/dubited.544192

Çifci, U. (2018b). Üç boyutlu tasarım ve imalat teknolojilerinin imalat için tasarıma olan etkilerinin incelenmesi. Yüksek Lisans Tezi, Düzce Üniversitesi Fen Bilimleri Enstitüsü, Düzce.

Durgun, İ. (2015). Tabakalı hizlı prototipleme yöntemlerinin karşılaştırılması. XIII. Otomotiv ve Yan Sanayi Sempozyumu ve Sergisi (s. 13). İstanbul.

Ekici, B. ve Yaltırık, H. (2009). FDM (fused deposition modeling) yöntemi ıle çalışan hızlı prototip cihazlarında kullanılan abs filament telin üretilmesi. Makine Tasarım ve İmalat Dergisi, 11(1), 39-34.

Güneş, M. (2018). Kompozit baskı yapan üç boyutlu yazıcının geliştirilmesi. Yüksek Lisans Tezi, Karabük Üniversitesi, Fen Bilimleri Enstitüsü, Karabük.

Gür, Y. (2017). Üç boyutlu masa üstü yazıcı ile matematiksel bir modelden gerçek bir nesnenin dijital üretimi. Balıkesir Üniversitesi Fen Bilimleri Enstitüsü Dergisi, 19(2), 237-245. https://doi.org/10.25092/baunfbed.342365

Hakan Verdu Martinez, E. ve Can, E. (2016). Bilgisayar destekli seramik üretim yöntemi olarak üç boyutlu yazıcılar ve günümüz koşullarında uygulama örneği. Sanat \& Tasarım Dergisi, 6(1), 1-14. https://doi.org/10.20488/www-stdanadolu-edu-tr.290760

Huang, S.H., Liu, P., Mokasdar, A. and Hou, L. (2013). Additive manufacturing and its societal impact: A literature review. The International Journal of Advanced Manufacturing Technology, 67(5-8), 1191-1203. https://doi.org/10.1007/s00170-0124558-5

Kalmaz, C. (2020, Mayıs 20). Sigma3D yerli açık kaynak yazıc1. https://3boyutlubaski.com/2020/04/sigma3dyazici-yapimi-asamalari/

Kartal, F. (2017). Taguchi metodolojisi ile eriyik yığma modelleme süreci parametrelerinin optimizasyonu. International Journal of 3D Printing Technologies and Digital Industry, 1(1), 49-56.
Korkmaz, B. (2014). 3B Yazıcı: Atlantik ve avrasya rekabetinde yeni bir faktör. U.Ü. Sosyal Bilimler Enstitüsü Dergisi, 7(2), 17-30.

Kun, K. (2016). Reconstruction and development of a $3 d$ printer using fdm technology. Procedia Engineering, 149(2016), 203-211. https://doi.org/10.1016/j.proeng.2016.06.657

K, Demir., E.B., Çaka, C., Tuğtekin, U., Demir, K., İslamoğlu, H. ve Kuzu, A. (2016). Üç boyutlu yazdırma teknolojilerinin eğitim alanında kullanımı: Türkiye'deki uygulamalar. Ege Eğitim Dergisi, 17(2), 481-503. https://doi.org/10.12984/egeefd.280754

Maden, H., Kamber, Ö., Dipcin, E., Uğur, H., Özsarıkaya, B. ve İğneci, A. (2016). FDM Teknoloji 1le üretilen prototip parçalarının hataları ve hataların önlenmesi. 3 Boyutlu Bask1 Teknolojileri Uluslararası Sempozyumu (ss. 5659). İstanbul.

Madhavan Nampoothiri, K., Nair, N.R. and John, R.P. (2010). An overview of the recent developments in polylactide (pla) research. Bioresource Technology, 101(22), 8493-8501. https://doi.org/10.1016/j.biortech.2010.05.092

Murariu, M., Laure-Dechief, A., Paint, Y., RamyRatiarison, R., Dubois, P. and Marie-Raquez, J. (2014). Recent advances in production of poly(lactic acid) (pla) nanocomposites: A versatile method to tune crystallization properties of pla. Nanocomposites, 1(2), 71-82. https://doi.org/10.1179/2055033214Y.00000000 08

Novakova-Marcincinova, L., Novak-Marcincin, J., Barna, J. and Torok, J. (2012). Special materials used in fdm rapid prototyping technology application. INES 2012 - IEEE 16th Int. Conf. Intell. Eng. Syst. Proc. (pp. 73-76). Lizbon. https://www.doi.org/10.1109/INES.2012.62498 05

Olivera, S., Muralidhara, H.B., Venkatesh, K., Gopalakrishna, K. and Vivek, C.S. (2016). Plating on acrylonitrile-butadiene-styrene (abs) plastic: A review. Journal of Materials Science, 51(8), 3657-3674. https://doi.org/10.1007/s10853-015-9668-7

Rayna, T. and Striukovai, L. (2009). The impact of 3d printing technologies on business model innovation. Digital Enterprise Design and Management, 3(2), 358-369. https://doi.org/10.1007/978-3-319-04313-5_11

Rindfleisch, A., Hern, M. and Sachdev, V. (2017). The digital revolution, $3 \mathrm{~d}$ printing, and innovation as data. The Journal of Product Innovation Management, 34(5), 681-90. https://doi.org/10.1111/jpim.12402 
Satyanarayana, B. and Prakash, K.J. (2015). Component replication using $3 \mathrm{~d}$ printing technology. Procedia Materials Science, 10(2015), 263-269. https://doi.org/10.1016/j.mspro.2015.06.049

Sigma3D-PowerABS Fiziksel, Mekanik ve Termal Özellikleri. (2020a, 10 Nisan). Erişim adresi https://sigma3dprinter.com/belgeler/powerabstest-sonuçlari.pdf.

Sigma3D-PowerPLA TDS. (2020b, 10 Nisan). Erişim adresi

https://sigma3dprinter.com/belgeler/PowerPLA TDS.pdf.

Wong, J.Y. and Pfahnl, A.C. (2014). 3D Printing of surgical instruments for long-duration space missions. Aviation, Space, and Environmental
Medicine,

85(7),

$758-763$.

https://doi.org/10.3357/ASEM.3898.2014

Wong, K. and Hernandez, A. (2012). A review of additive manufacturing. 2012 ISRN Mechanical Engineering. (pp. 1-10). https://doi.org/10.5402/2012/208760

Yampolskiy, M., Skjellum, A., Kretzschmar, M., Overfelt, R.A., Sloan, K.R. and Yasinsac, A. (2016). using $3 \mathrm{~d}$ printers as weapons. International Journal of Critical Infrastructure Protection. 14(2016), 58-71. https://doi.org/10.1016/j.ijcip.2015.12.004

Wikimedia File: FDM by Zureks Png. (2018, 21 May). Access adress https://commons.wikimedia.org/wiki/File:FDM _by_Zureks.png 